\title{
Isolated fallopian tube torsion
}

\section{Bandamma N. S., Prema Prabhudev, S. Pooja*}

Department of Obstetrics and Gynecology, SSIMS and RC Davangere, Karnataka, India

Received: 03 January 2021

Accepted: 06 February 2021

\section{*Correspondence:}

Dr. S. Pooja,

E-mail: poodasarath@gmail.com

Copyright: ( ) the author(s), publisher and licensee Medip Academy. This is an open-access article distributed under the terms of the Creative Commons Attribution Non-Commercial License, which permits unrestricted non-commercial use, distribution, and reproduction in any medium, provided the original work is properly cited.

\begin{abstract}
Fallopian tube torsion is a rare cause of acute abdomen, occurring commonly in females of reproductive age. It lacks pathognomonic symptoms, signs, or imaging features, thus causing delay in surgical intervention. Current study report one case of isolated fallopian tube torsion in adolescent girl. In this case a 13 year old patient presented with acute pain in the right iliac region associated with 3 episodes of vomiting for one day and severe tenderness on examination. Laparoscopy revealed right sided twisted fallopian tube associated with gangrenous fimbrial end. The tube was untwisted and salpingectomy done. Salpingectomy was done as the tube was gangrenous. Fallopian tube torsion, though rare, should be considered in women of reproductive age with unilateral pelvic pain. Early diagnostic laparoscopy is important for an accurate diagnosis and could prevent the rupture of the gangrenous tube.
\end{abstract}

Keywords: Torsion, Fallopian tube, Salpingectomy, Laparoscopy, Pelvic pain

\section{INTRODUCTION}

Isolated torsion of fallopian tube is a rare entity occurring in 1 in 1.5 million women. ${ }^{1}$ It is a surgical emergency, where prompt diagnosis and timely surgical intervention are vital to prevent rupture of the fallopian tube. It is rarely diagnosed preoperatively due to its rarity, lack of definitive diagnostic signs, and similarity to other cases of acute abdomen. We are reporting one case in adolescent girl, where early intervention could prevent peritionitis if rupture of fallopian tube could have occurred.

\section{CASE REPORT}

A 13 years old girl came with acute abdomen with tenderness in right iliac region, with 3 episodes of vomiting. UPT was done negative. Vitals were stable on admission. Pain relieved on medications. Emergency scan done. Bilateral bulky ovaries with multiple cysts on right side and solitary cyst on left side, Mesenteric lymphadenopathy noted, minimal free fluid in RIF. Acute abdominal pain relieved on medications. Next day, one episode of acute abdomen, PR;100 bpm, BP; 110/70 mmhg. P/A; tenderness present in right iliac fossa. Her hemoglobin value was $12 \mathrm{~g} / \mathrm{dl}$ and white blood cell count was $12,500 \mathrm{~mm} 3$, platelet count; 3.43 lakhs/cu mm, urea; 18.3 and creatinine; 0.5 . Her symptoms did not resolve on conservative management. Urine routine showed 1-2 pus cells. Patient was taken for diagnostic laparoscopy; intraoperatively. In left ovary clear cyst of $4 \times 5 \mathrm{~cm}$ was noted, left fallopian tube was observed to be normal, right ovary was also observed to be normal, right fallopian tube had undergone four twists around the axis with gangrenous changes noted in ampullary and fimbrial end. Ampullary end dilated upto $4 \times 4 \mathrm{~cm}$. Untwisting of right fallopian tube was done. Right side total salpingectomy was done. Left side ovary clear cyst was punctured and clear fluid was drained. Post operative period was uneventful and patient was discharged in three days.

\section{DISCUSSION}

IFTT occurs mostly in 12-15 year olds and is rare before menarche or during menopause. IFTT may occur due to intrinsic and extrinsic causes. ${ }^{2}$ Suggested mechanisms for its etiology are the intrinsic and extrinsic tubal factors. Intrinsic causes include congenital anomalies, excessive 
tubal length, acquired pathology, hydrosalpinx, haematosalpinx, neoplasm, previous surgery, autonomic dysfunction and abnormal peristalsis.

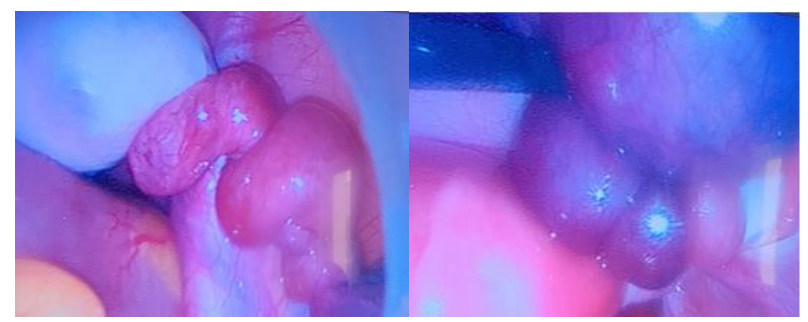

Figure 1: Twist of unilateral fallopian tube.

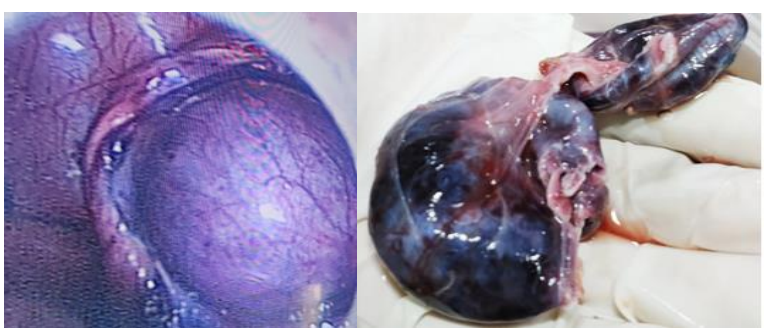

Figure 2: Gangrenous ampullay and fimbrial part of fallopian tube.

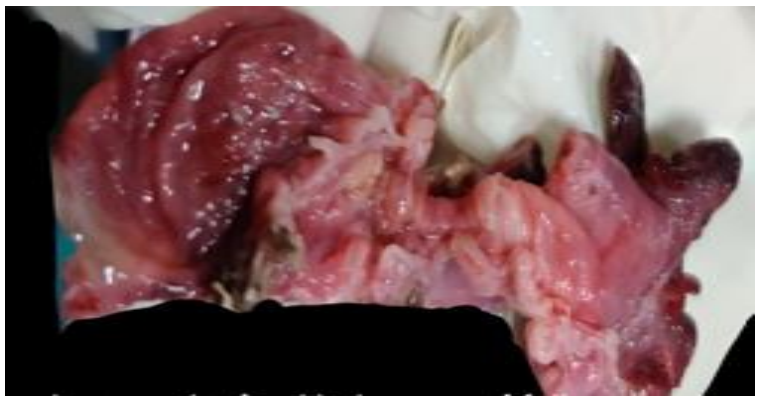

Figure 3: Isthmic and infundibular part of fallopian tube.

Extrinsic causes include changes in the neighbouring organs, neoplasm, adhesions, pregnancy, mechanical factors, movement or trauma to the pelvic organs, and pelvic congestion. ${ }^{3,4}$ Imaging studies including conventional ultrasound and color Doppler are beneficial aids to diagnosis but presence of normal flow does not always rule out torsion. ${ }^{5}$ In current study patient, Doppler findings were normal and hydrosalpinx was misdiagnosed as an ovarian cyst, as was also reported by Lau. ${ }^{6}$ Detorsion can be performed in early stages in normal looking adnexa, so that the blood supply is resumed, as done by Pinkert in an 18 year old female with an edematous ovary and haematosalpinx. ${ }^{7,8}$ In adolescents, treatment can be done conservatively with aspiration of the hydrosalpinx, but if it recurs, salpingectomy is recommended to prevent detorsion.
Oophoropexy for ovarian torsion is easy to be done by many tools either suturing to the lateral pelvic wall, plication of the ovarian ligament or even fixation to the back of the uterus, but it is little bit difficult to do it for pregnant women with less manipulation. ${ }^{9}$

\section{CONCLUSION}

Fallopian tube torsion should be considered in the differential diagnosis of acute lower abdominal and pelvic pain in all adolescent girls. Operative laparoscopy seems to be the most suitable management strategy.

Funding: No funding sources Conflict of interest: None declared

Ethical approval: Not required

\section{REFERENCES}

1. Toyoshima M, Mori H, Kudo K, Yodogawa Y, Sato $\mathrm{K}$, Kudo $\mathrm{T}$, et al. Isolated torsion of the fallopian tube in a menopausal woman and a pre-pubertal girl: two case reports. J Med Case Rep. 2015;9:258.

2. Youssef AF, Fayad MM, Shafeek MA. Torsion of the fallopian tube. A clinico-pathological study. Acta Obstet Gynecol Scand. 1962;41:292-309.

1. Krissi H, Shalev J, Bar-Hava I, Langer R, Herman A, Kaplan B. Fallopian tube torsion: laparoscopic evaluation and treatment of a rare gynecological entity. J Am Board Fam Pract 2001;14:274-7.

2. Bernardus RE, Van der Slikke JW, Roex AJ, Dijkhuizen GH, Stolk JG. Torsion of the fallopian tube: some considerations on its etiology. Obstet Gynecol. 1984;64:675-8.

3. Pena JE, Ufberg D, Cooney N, Denis AL. Usefulness of Doppler ultrasonography in the diagnosis of ovarian torsion. Fertil Steril.2000;73:1047-50.

4. Lau HY, Huang LW, Chan CC, Lin CL, Chen CP. Isolated torsion of the fallopian tube in a 14-year-old adolescent. Taiwan J Obstet Gynecol. 2006;45(4): 363-5.

5. Breech LL, Hillard PJ. Adnexal torsion in pediatric and adolescent girls. Curr Opin Obstet Gynecol. 2005; 17:483-9.

6. Pinkert M, Klein Z, Tepper R, Beyth Y. Hydrosalpinx with adnexal torsion in an adolescent virgin patient-A diagnostic dilemma: case report and review of the literature. J Pediatr Adolesc Gynecol. 2006;19:297-9.

7. Hosny TA. Oophoropexy for ovarian torsion: a new easier technique. Gynecol Surg. 2017;14:7.

Cite this article as: Bandamma NS, Prabhudev P, Pooja S. Isolated fallopian tube torsion. Int J Reprod Contracept Obstet Gynecol 2021;10:1219-20. 